\title{
An Interactive Multimedia E-learning Material on Fiber Welding and Measurement
}

\author{
Yuen Wu, Mingjia Cai* \\ No. 1, Daxue Rd., Yanchao Dist., Kaohsiung City 824, Taiwan \\ "Corresponding author.Email: abc62563145@gmail.com

\begin{abstract}
The purpose of this research aims to design a set of interactive-multimedia-aided courses on optical fiber maintenance systems which enable the trainees simulate the operation of the maintenance facilities and safety precautions on the computer. The simulation courses will enhance the efficiency of the training, increase the number of training, and reduce training costs.
\end{abstract}

Keywords: Communication technology, mobile learning, computer-assisted instruction, e-learning,

collaborative learning

\section{INTRODUCTION}

The technical development of communication maintenance personnel must rely on the way of predecessors to teach maintenance knowledge and inspection methods, and it must waste a lot of time on personnel training. Improper wiring planning inside and outside the communication room and unfamiliar with the telecommunication line architecture inside the room will make it difficult to add and maintain lines in the future. For the operation of optical fiber equipment and the implementation of each item, there must be relatively equivalent equipment for education and training. The number of equipment and environment for personnel training is often affected by terrain, resulting in very limited training effectiveness. In addition, the maintenance of optical fiber, copper cables and faulty lines of various equipment requires accumulation of experience. Traditional equipment operation courses will face complicated technical problems, which will cause the dynamic display of the system and the change of the switch state to be difficult to understand and present. It can only be represented by text and static pictures, which will make teaching more difficult. The course of communication line implementation will face complicated technical problems, especially in the implementation of optical fiber, which will cause teaching difficulties. Due to the shortage of funds for the construction of training venues, the number of equipment is limited, The goal of one person and one machine cannot be achieved, resulting in limited training numbers. In addition, teachers' teaching quality is inefficient due to factors such as the level of learners and insufficient equipment. Wireless networks are highly mobile, so some scholars have proposed the concept of Mobility E-learning, also referred to as M-learning for short.

Literally, action is the most important element of E-learning. Mobile devices allow learners to learn digitally and free them from the constraints of time and place. The user walks from indoor to outdoor and freely acquires the knowledge they want to learn in a synchronous or asynchronous manner. The definition of Mobile learning, generally speaking, it can be learned at any time, any place and any device, which is called Mobile learning [2]. Literature [3] considers that mobile learning is the behavior of learning through mobile computing devices, such as Palm, WinCE, and mobile phones. Literature [4] considers that mobile learning is the meeting point of mobile technology and E-learning, which produces an experience that can be learned at any time and anywhere, that is, the moment to enjoy learning through PDA or mobile phone. The purpose of this article is to design and produce a set of simulation self-study textbooks that can be applied to the communication technology license examination. Using E-Learning methods and courses to enable learners to have basic knowledge before performing practical operations can effectively improve learning motivation and solve the problem of limited teaching resources. Learners preview before class, then enter the practical classroom, and pass the quizzes to confirm the learners' proficiency before they can operate the equipment to save classroom hours. This article uses the Smart Apps Creator software to build a self-learning system for Class B communication technology. It allows learners to use computers and mobile devices to learn and interact with the content of the course to understand the content of the technical test of communication technology. 


\section{LITERATURE AND TECHNICAL DISCUSSION}

\subsection{Mobile Learning}

\subsubsection{Current mobile learning methods}

Mobile learning can be defined as teaching and learning using mobile devices, such as mobile phones, wearables, and laptops. It has features such as portability, social connectivity, and personalization [4]. Mobile devices make computer-assisted instruction easier to ask and fuse learning and teaching scenarios together.

In terms of promoting innovative teaching methods, mobile teaching not only supports traditional lecture-type teaching, but also enhances the effectiveness of multiple teaching methods. For example, collaborative learning [5], query learning, and game learning methods to research and emotional traits from topics in different domains of cognitive abilities are all affected by the diverse applications of mobile devices.

\subsubsection{Mobile learning research}

From the literature [6] found a sample of articles using mobile devices to promote seamless learning, 10 functions can be extracted, including formal and informal learning in context, personalization and social learning in interaction types, time and place across multiple studies. The narrative research in [7] reviews 18 different empirical studies, showing that laptops use different hours per week, ranging from a few days to as little as an hour. Computers are most often used for searching, and then for expression and communication. Most studies show that students are motivated to use laptops and feel more motivated and engaged in learning. A systematic analysis of revealed that mobile learning research on PK-12 education focuses on science, while primary school is the main object of research. Several studies have qualitatively and comprehensively studied Mobile Computer Supported Collaborative Learning (MCSCL)and concluded that: In terms of mobility and immediateness of feedback, MCSCL is superior to non-mobile, and MCSCL also has a positive impact on learner interactions, but does not necessarily affect their higher-order thinking. The literature [8] defines MCSCL, which refers to the use of communication handheld mobile devices to construct a cooperative learning environment to guide learners in cooperative learning.

\subsection{Digital Textbook Development Mode}

(Analysis Design Develop Implement and Evaluate) [9]. It is based on the logical sequence of instructional design, and divides the systematic instructional design pattern into five stages: analysis, design, development, implementation, and evaluation. Each stage includes certain steps. Teachers should systematically determine teaching goals, analyze learner characteristics and starting behavior, analyze teaching content, design teaching strategies and activities, develop teaching materials and produce teaching media, implement teaching, implement evaluate and revise the teaching process, in order to achieve the predetermined teaching goals and achieve ideal teaching results [10].

\section{SYSTEM ANALYSIS AND DESIGN}

At present, learners of optical fiber maintenance training classes or people who want to self-learn optical fiber maintenance can only learn about optical fiber maintenance from books or through the explanations of their predecessors; In addition, teachers often use briefings or actual equipment for teaching. To sum up the above questions, this textbook provides more meta and vivid ways to meet the needs of teachers and learners.

\subsection{Method for the Construction of Teaching Materials}

This teaching material is made by using software such as SimMAGIC eBook interactive multimedia e-book editing software and Microsoft Powerpoint 2013; The content of the textbook is compiled by referring to the optical fiber part of the Communication Technology $\mathrm{B}$ (telecommunications line). The pictures used in the textbooks are mostly self-captured, and most of them have been edited and removed backgrounds. Because the shooting effect of the block displayed on the device screen is not good, it is displayed in other ways, and it is divided into two categories according to the device display screen: The first type is that the LCD display can be compiled by Microsoft PowerPoint 2013 according to the display style; The second category is the color LCD screen display. For example, there are pictures and videos captured by the AV output capture card on the video output terminal. In this way, the effect of simulation can be improved. It is hoped that a set of high-simulation optical fiber equipment multimedia auxiliary teaching materials can be developed for teachers and learners in need for teaching and learning.

\subsection{Steps to Make Teaching Materials}

This teaching material is built by the teaching design of ADDIE. ADDIE refers to the design of teaching materials and teaching activities in the area of e-learning; It is an 
abbreviation of five English words, which includes five steps: Analysis, Design, Development, Implementation, and Evaluation.

\subsubsection{Analysis}

Confirm the design theme: Perform research analysis on the objects used to understand what hardware teaching the objects need, and confirm the design theme to avoid deviating from the theme. Master the concept: what are the related concepts? How to have a concept? What concepts should learners have first? Mastering Questions: Any related questions? What concepts are involved in the question? What phenomena are involved in the question? Can experiments solve problems? Mastering Phenomenon:
What are the related phenomena? What concepts are involved in the phenomenon? What problems are involved in the phenomenon? How to reproduce the phenomenon? What media is relevant? Any related teaching aids? Any related videos? Any related animations? Any related pictures?

In the subject section, this study is based on the examination and test materials of the B-level technical skills test of the Communication Technology (Telecommunication Line) issued by the Skill Evaluation Center of Workforce Development Agency, Ministry of Labor. The textbook is divided into the following five steps: optical power meter calibration, connector loss measurement, optical fiber chain construction and contact loss measurement, A-to-B chain optical power loss measurement, and B-to-A chain optical power loss measurement in Figure 2.

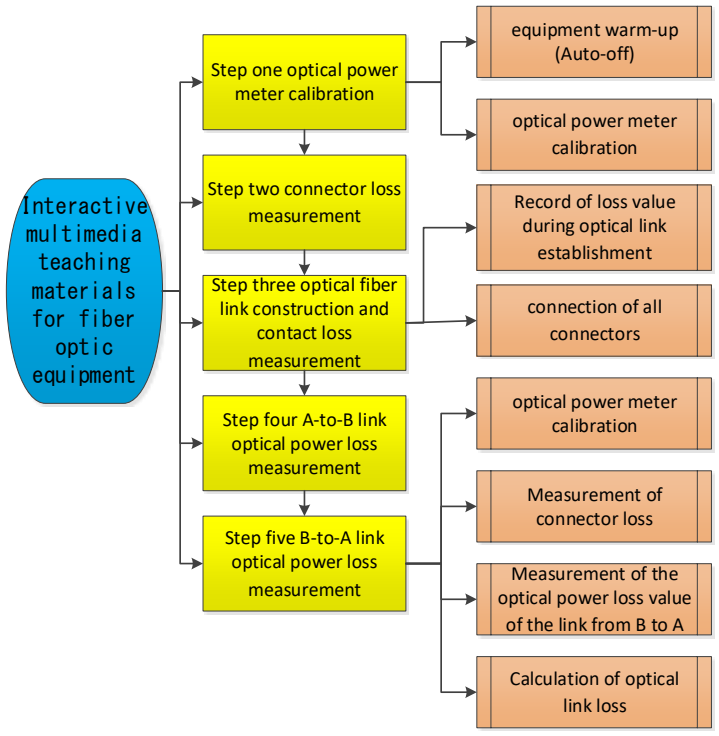

Figure 1 Structure diagram of textbook content

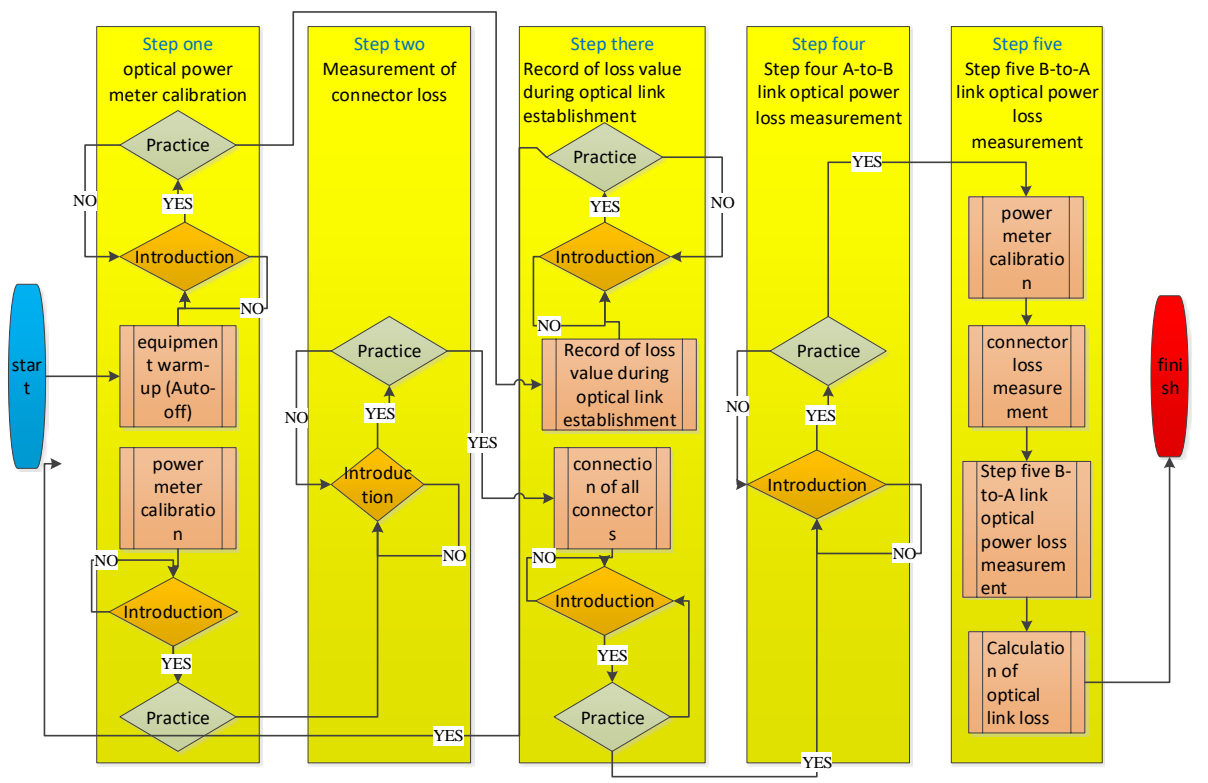

Figure 2 Flowchart of textbook structure 
SimMAGIC eage, and can also be converted into iOS or Android system and provide touch operation. Therefore, it is recommended to use touch devices on hardware resources, such as tablet computers or touch screens, in order to complement each other.

\subsubsection{Design}

In teaching design, the first is the introduction and demonstration of teaching, so that learners understand the course flow and action requirements. After being proficient, the learner then enters the exercise to test whether the learner fully understands the teaching steps. teaching steps. In the operation continuation function of this textbook, when the learner enters the sub-project, they can choose to practice directly or follow the introduction steps; The introduction part will complete all required actions in a guided way, so that users can easily understand the action requirements before entering the practice chapter. Test whether the learner can complete the program without prompting, and then move on to the next step or sub-project until they are proficient, and complete step by step to step 5 . The architecture flowchart is shown in Figure 2.

\subsubsection{Construction}

In order to make the picture of the device clear, this study uses a practical projector to shoot all the devices to complete the pre-shooting of the gallery.Pay attention to the following when shooting: choose the background as simple as possible, and use the projector's own lighting and focus adjustment to make the picture taken clear, so as to remove backgrounds; In addition, in the 360-degree shooting part, draw 12 scales on the circular rotating disk, place the equipment to be taken in the center of the turntable, take a photo at each scale, and each device needs a total of 12 pictures in the gallery.

\subsubsection{Development}

The library and video library have been completed during the construction phase. According to the design phase of the architecture and flowchart, the equipment library and movie library are combined with SimMAGIC eBook interactive multimedia e-book editing software to produce.

\subsubsection{Evaluation}

Donald Kirkpatrik once proposed a hierarchical evaluation model, which divides the evaluation into four levels, and the higher the level, the deeper the evaluation: The first level of assessment: assessing the learner's response to learning, the second level of assessment: assessing whether the learner really learned (including various knowledge and skills),
Level 3 assessment: assessing learners' application of their learning to life and work, level 4 assessment: assessing the business benefits of e-learning, Therefore, in addition to the evaluation model, it also needs to develop the indicators used in the actual evaluation to understand the effectiveness and quality of online teaching at various levels of education. The test is completed after the completion of this textbook. The test section is divided into the following two types of users: developers provide assistance when learners and lecturers perform operations, and record the problems encountered by learners, and modify the unsmooth parts. Feedback from teachers: This textbook provides very good teaching results. In terms of operation, as the physical equipment is converted to multimedia, and the projection teaching with a single-gun projector is used, the learners can clearly see the operation steps and avoid many people watching the same equipment. It greatly improves the quality of teaching.

\section{SYSTEM IMPLEMENTATION RESULTS AND TESTS}

The textbook first introduces the equipment used in this internship, so that learners can understand the name of each device and confirm whether they know them. If the learners are very familiar with the use of various equipment, they can start this textbook directly. Conversely, for the unclear parts, the learner first reads the appearance and operation of this equipment to increase the proficiency of the equipment. After confirming the knowledge, they start to study this textbook. In addition to equipment introduction, this textbook also uses the method of illustrations to present the test room settings, making it easier for learners to follow up the actual machine operation phase. The topic divides the process into the following parts:equipment warm-up, optical power meter calibration, connector loss measurement, connection of all connectors, A-to-B link and B-to-A link. The main directory connects the parts in series, but the first few steps of the seventh part (link from B to A) are the same as the sixth part (link from A to B), except that the last steps are different, so the seventh step is to add directly to the main directory for presentation.

The learner enters the first unit (equipment warm-up) after fully operating the equipment. At the beginning of each stage, first explain the requirements of the test questions to let learners know what items need to be done in this unit.

\section{BENEFIT EVALUATION AND CONCLUSION}

The main purpose of this research is to develop a set of interactive multimedia computer-aided teaching materials, hoping to improve the teaching effectiveness of fiber fusion and measurement through the integration of text, pictures and videos. The results of the development and testing of 
this teaching material can be summarized a few conclusions:

\subsection{Research Contributions}

The contribution of this research is divided into two parts: the cost and the number of trainers.

\subsubsection{Cost}

The use of this supplementary teaching material can effectively reduce training costs. To understand the effectiveness of cost reduction, you need to know the general training costs. The quantity of equipment and consumables is mainly based on the quantity required for the test questions, so it is based on training once. Equipment and consumables need to be reused and used times: Cotton swabs and heat shrink tube are disposable consumables. The single-mode fiber optic jumper wire tail fiber is repeated 20 times to avoid loss caused by insertion; The single-mode fiber pigtail is cut $10 \mathrm{~cm}$ each time, and it is expected to cut 2 times. If it is less than 3 meters, it must be replaced if it does not meet the requirements of the test. Its repetition is 10 times; The single-mode virtual optical fiber is cut $10 \mathrm{~cm}$ each time and is expected to be cut twice. If it is less than 200 meters, it does not meet the test requirements and must be replaced; The welding rod of the splicing machine should be replaced 5000 times according to the original recommendation. The optical power meter and stable light source must be used for 2 hours each time, and after 200 hours of use after testing, they must be returned to the factory for calibration to meet the accuracy required by the test questions. The number of repetitions is 100 times. The total is calculated as shown in formula (1). The training cost for one person is NT \$ 953 .

$$
\text { Subtotal }=(\text { price } / \text { repetitions }) \times \text { quantity }
$$

Statistics of traditional teaching costs are as follows: The number of trainers in the field of this research experiment is 12 people. In the training frequency part, the average learner needs a total of 17 training sessions from beginning to proficiency. However, after the training is completed, there is a period of time before the actual test. Many learners ca n't continue to practice when they take the test, and it 's easy to forget the operation process and precautions, which makes it impossible to get the license. Therefore, many learners will return to the training ground before taking the test, reviewing 2 or 3 times to return to the proficiency level, in order to successfully obtain the certificate. According to formula (2), the total training cost is about NT \$228,000.

$$
\begin{gathered}
\text { Total }=\text { Subtotal Sum } \times \text { Number of Exercises } \times \text { Number } \\
\text { of People }
\end{gathered}
$$

The auxiliary teaching materials developed in this study allow learners to understand the test requirements, correct equipment operation methods, and test procedure on a computer, and make sure that learners can meet the design goals of the institute before they start using actual equipment for implementation. In this way, the consumption of equipment and consumables can be reduced. With the assistance of this textbook, only 8 actual machine operations are needed to achieve proficiency; Review before the exam: Learners use this supplementary textbook to review, and they only need to practice once at the training venue to get back to proficiency. According to formula (2), the total training expenditure is about NT \$ 103,000. Compared with the traditional teaching method, the training expenses are reduced by NT $\$ 125,000$, which means that the use of this teaching material can really reduce the training cost.

\subsubsection{Number of trainees}

Questions are divided into 2 stations, and each station has two types of questions, which are divided into 4 question groups. The traditional method divides the learners into four groups, according to the number of equipment in the standard examination venue of the Ministry of Labor. As shown in Table 5-2, there are three complete sets of equipment, which can provide 3 people per group to use; The training method first adopts exchange question groups, and then exchanges stations ; The learners of the second group of the second station and the second group of the second station will exchange after the study is completed, and then exchange with the learners of the first station after the second station; In this way, using the formula (3), four sets of questions and three sets of equipment can reach a training volume of 12 people.

Number of questions $\mathrm{x}$ number of equipment (sets) = maximum training volume (3)

The above is the traditional training mode. After using this auxiliary teaching material, the training method has changed slightly; The exchange method between the stations is the same. The only change is to use this auxiliary teaching material to practice before using the actual equipment. Each learner will have different working backgrounds and degrees, so the time for them to enter the actual machine operation will be different. Using auxiliary teaching materials to practice can reduce the use time of the real machine. The study found that the use time of the equipment was reduced by more than half, and the number of trainers could be increased. Finally, this study doubled the number of trainers per group and provided a total of 24 trainers.

\subsection{Conclusion}

The biggest difference between interactive multimedia aided teaching materials and traditional teaching is that traditional teaching uses equipment to implement directly. Because of differences in understanding of equipment, it is easy for learners to fumble and learn in mistakes, and waste 
a lot of time or incorrectly operate the equipment. In addition, due to the limitation of the number of equipment, the number of trainees cannot be increased; The auxiliary teaching materials of this research can achieve the following five points of help. The first point: help students quickly understand the equipment use methods and safety operation instructions, the second point is to quickly enter the learning situation and improve teaching effectiveness. The third point is to reduce the damage of high-priced equipment due to improper operation. The fourth point is to reduce the number of times the equipment is used and reduce the damage rate of high-priced equipment. The fifth point is to increase the computer-assisted teaching area of the skills test to increase the number of trainees. The sixth point is to provide learners with exercises after class and before the exam.

\section{REFERENCES}

[1] Chabra, T., \& Figueiredo, J. (2002), How To Design and Deploy Handheld Learning., Retrieved September 20 , 2005.

[2] Quinn, C. (2002). mLearning: Mobile, Wireless, In-Your-Pocket Learning. Retrieved September 20 ,2005.

[3] Harris, P. (2001). Goin' Mobile. Retrieved October 15,2005 .

[4] Tezer, M., \& Cimşir, B. T. (2018). The impact of using mobile-supported learning management systems in teaching web design on the academic success of students and their opinions on the course. Interactive Learning Environments, 26(3), 402-410.

[5] Gao, Y., Liu, T. C., \& Paas, F. (2016). Effects of mode of target task selection on learning about plants in a mobile learning environment: Effortful manual selection versus effortless QR-code selection. Journal of Educational Psychology, 108(5), 694-704.

[6] Suarez, A., Specht, M., Prinsen, F., Kalz, M., \& Ternier, S. (2018). A review of the types of mobile activities in mobile inquiry-based learning. Computers \& Education, 118, 38-55.

[7] Wong, L. H., \& Looi, C. K. (2011). What seams do we remove in mobile assisted seamless learning? A critical review of the literature. Computers \& Education, 57, 2364-2381.

[8] Fleischer, H. (2012). What is our current understanding of one-to-one computer projects: A systematic narrative research review. Educational Research Review, 7, 107-122.
[9] Zurita,G.,\& Nussbaum, M.(2004).Computer supported collaborative learning using wirelessly interconnected handheld computers.Computers \& Education,42,289-314.

[10] Dick, W., \& Carey, L. (1996). The systematic design of instruction. New York: HarperCollins Publishing. 